\title{
Comparing patterns of human harvest and predation by Eurasian Iynx Lynx lynx on European roe deer Capreolus capreolus in a temperate forest
}

\author{
Miha Krofel ${ }^{1,2, *}$, Klemen Jerina ${ }^{1}$, Franc Kljun ${ }^{2}$, Ivan Kos ${ }^{2}$, Hubert Potočnik ${ }^{2}$, \\ Nina Ražen ${ }^{2}$, Petra Zor ${ }^{2}$, Anamarija Žagar ${ }^{2}$ \\ ${ }^{1}$ Dept. for Forestry and Renewable Forest Resources, Biotechnical Faculty, University of \\ Ljubljana, Večna pot 83, SI-1001 Ljubljana, Slovenia \\ ${ }^{2}$ Dept. for Biology, Biotechnical Faculty, University of Ljubljana, Večna pot 111, SI- \\ 1001 Ljubljana, Slovenia \\ *Correspondent: \\ tel.: +38651228717 \\ fax: +38612571169 \\ e-mail: miha.krofel@gmail.com
}

\begin{abstract}
Human harvest is the most important mortality factor for wild ungulates in Europe and can affect several aspects of ungulate biology. There is a growing concern about possible negative sideeffects of human harvest. To better understand differences between human and natural mortality we compared the extent, age and sex structure, nutritional condition, spatial and temporal distribution of human harvest and natural predation by the Eurasian lynx Lynx lynx on the European roe deer Capreolus capreolus, the most abundant wild ungulate in Europe. Compared to the human harvest, lynx were less likely to kill fawns and yearlings than adults, and among adult deer lynx were more likely to kill females. Proportion of roe deer with fat-depleted bone marrow was higher among lynx prey than among harvested animals. Average lynx kill rate was estimated to 47.8 roe deer / year and lynx predation was considerably lower than the human harvest in the same area. While human harvest increased with higher roe deer density, lynx predation was similar across the gradient of roe deer densities. Comparison with other countries indicated that differences between human harvest and natural mortality of ungulates vary considerably in different parts of Europe. Variation in hunting practices and, even more importantly, carnivore
\end{abstract}


predation may have an important role in buffering unwanted side-effects of harvest of wild ungulates.

KEY WORDS: Dinaric Mountains, hunting, mortality, Slovenia, ungulates, wildlife management.

\section{INTRODUCTION}

Nowadays, human harvest is the most important mortality factor for the wild ungulates in Europe (Festa-Bianchet 2003; Apollonio et al. 2010). Hunting can strongly affect demographic parameters (Langvatn and Loison 1999; Ginsberg and Milner-Gulland 1994), genetic (Harris et al. 2002) and morphological characteristics (Coltman et al. 2003), reproduction, social structure, behavior and evolution of ungulates in the harvested populations (Festa-Bianchet 2003; Milner et al. 2007; Apollonio et al. 2010; Mysterud 2010; Proaktor et al. 2007; Ciuti et al. 2012). Since selective hunting could differ considerably from natural mortality, among which predation is usually the most important cause (Jedrzejewski et al. 2011), there is a growing concern about possible negative sideeffects of human harvest (Ginsberg and Milner-Gulland 1994; Proaktor et al. 2007; Apollonio et al. 2010). However, there have been surprisingly few studies comparing ungulate mortality patterns between human harvest and natural predation within the same ecosystem (but see for example Andersen et al. 2007 and Wright et al. 2006).

The European roe deer Capreolus capreolus is today by far the most abundant ungulate species in Europe and one of the most important game species with total number estimated to around 10 million animals and annual harvest of 2.9 million animals (Apollonio et al. 2010; Linnell and Zachos 2011). Good understanding of differences in human harvest and natural mortality is necessary to establish effective management of wild ungulates (Jedrzejewski et al. 2011). Throughout Europe, hunting systems vary greatly in respect to their management objectives, hunting intensity, hunting practices, and restrictions regarding hunting season and demographic structure of harvested animals (Putman 2011). For example, while in Scandinavia there are no sex and age prescribed hunting quotas and roe deer is concentrated at artificial feeding sites during winter (Andersen et al. 2007; 2010), in contrast in Slovenia there is prescribed and strictly controlled age and sex structure of removed animals and supplemental feeding of roe deer is not allowed (Adamič and Jerina 2010). To lower extent, differences among regions have also been observed in natural predation patterns, mainly as a consequence of environment productivity, winter severity, structure of ungulate community, demographic structure and nutritional condition of prey populations (Okarma 1995; Nilsen et al. 2009; Gervasi et al. 2011; Heurich et al. 2012). Therefore considerable variation in differences between hunting and natural mortality, as well as in the consequent side-effects of hunting, can be expected across various conditions throughout Europe.

We analyzed several aspects of human harvest of the European roe deer in a temperate forest in Dinaric Mountain Range in southern Slovenia and compared it with predation by the Eurasian lynx Lynx lynx in the same area. The Eurasian lynx is a mid-sized carnivore and solitary stalker, specialized in hunting small ungulates (Jedrzejewski et al. 1993; Breitenmoser and Breitenmoser-Würsten 2008). It is regarded as the most important predator of roe deer in Europe and its impact in general decreases with environment productivity (Jedrzejewska and Jedrzejewski 1998; Melis et al. 2009; 2010). We were interested in differences between human harvest and lynx predation in 1) sex and age structure of killed roe deer, 2) their nutritional condition, 3) extent of both mortality causes, 4) distribution of both mortality causes in space and in respect to the local roe 
deer densities, and 5) seasonal patterns of roe deer mortality. Results are discussed in the context of variation in differences between human and natural mortality in different environmental, biological and management settings throughout Europe and its importance for buffering unwanted side-effects of harvest of wild ungulates.

\section{MATERIALS AND METHODS}

\section{Study area}

The study was conducted in a temperate forest in the northern part of the Dinaric Mountains Range in Slovenia, Central Europe $\left(45^{\circ} 25^{\prime}-45^{\circ} 57^{\prime} \mathrm{N}\right.$ and $\left.14^{\circ} 10^{\prime}-15^{\circ} 10^{\prime} \mathrm{E}\right)$. The study area is characterized by a rugged karstic relief and the altitudes range from approximately $150 \mathrm{~m}$ a.s.l. to the peak of Mount Snežnik at 1,796 $\mathrm{m}$ a.s.l. The climate is temperate with annual temperature averaging $5-8^{\circ} \mathrm{C}$, and average annual precipitation of $1400-3500 \mathrm{~mm}$. The forest coverage is $79 \%$, with most of the area covered by Dinaric fir and beech forests Omphalodo-Fagetum. Average human density is 54 people / km² (Perko and Orožen Adamič 1998). Four native species of ungulates live in this area: roe deer, red deer Cervus elaphus, chamois Rupicapra rupicapra, and wild boar Sus scrofa. There are also few small and isolated introduced populations of mouflon Ovis ammon and fallow deer Dama dama. Besides Eurasian lynx, brown bear Ursus arctos and gray wolf Canis lupus are present in the area, as well as several species of smaller carnivores. Game species in Slovenia are the property of state and management is based on 10-year and yearly management plans prepared by the Slovenia Forest Service. Roe deer is the most widespread and most important game species in the country. Annually 35,00045,000 animals are harvested, which represent $79 \%$ of all recorded mortality for this species (Adamič and Jerina 2010). Large part of natural mortality usually remains unrecorded. Hunting season for the roe deer lasts from 1 May until 31 December (1 May until 31 October for adult and yearling males, 1 September until 31 December for fawns and adult females, and 1 May until 31 December for yearling females). During the study period age and sex structure of all human-caused mortality (i.e. harvest and road-kills) was prescribed as: $35-40 \%$ fawns, $20 \%$ yearlings, $40-45 \%$ adults and 1:1 sex ratio for yearlings and adults (Slovenia Forest Service 2007). The age and sex structure of harvested animals can differ from the prescribed structure, especially since sometimes more females are purposely incorrectly reported to have died from other causes in order to be able to shoot higher proportion of trophy animals and to save reproductive females (Poličnik et al. 2011). Supplemental feeding of roe deer is not allowed, but sometimes the feeding places intended for other species are visited also by the roe deer (Adamič and Jerina 2010). Eurasian lynx was reintroduced to Slovenia in 1973, about 65 years after its extinction, and in the first twenty years after reintroduction the population increased and expanded

rapidly (Kos et al. 2005). However, the population started decreasing in 1990s and today the lynx is considered the most endangered mammal in the region, with estimated 15-25 animals left in Slovenia in 2005-2009 (Kos et al. 2012). The main prey of Eurasian lynx in the study area is the roe deer, and the most important alternative prey is the edible dormouse Glis glis, each representing $79 \%$ and $7 \%$ of biomass consumed by lynx, respectively (Krofel et al. 2011).

\section{Data collection}

Wild ungulates removed in Slovenia are geo-referenced with $1 \mathrm{~km}$ accuracy and data on age, sex, date and cause of removal are collected in the central database (Adamič and 
Jerina 2010). Because in Slovenia age estimation of adults ( $\geqq 2$ years) is based only on visual estimation of tooth wear, which is unreliable for precise aging (Hewison et al. 1999), we used only three age categories (fawn, yearling or adult) for further analysis of data from this database, as it was shown that visual age estimation is reliable only for distinguishing between these three categories, for which also other morphological characters beside tooth wear can be used for aging (e.g. tooth eruption and growth, body size and shape, antler morphology; Jelenko et al. 2010). We used data of harvested roe deer from management units "Notranjska" and "Kočevska" from years 2006-2011 (n = 22,968 ), which corresponds to the time period and area where majority of lynx kills were found and the core area of lynx distribution in the country. From a subsample of 205 shot animals we collected mandibles and metatarsal bones to determine precise age and nutritional condition (see below for details).

To locate carcasses of ungulates killed by lynx we used snow-tracking of the unknown lynx and the location cluster analysis of telemetry data from the collared lynx (Krofel et al. 2013). In the period 2005-2012, eight lynx (five females and three males) were captured and equipped with telemetry collars (five with GPS-VHF collars and three with VHF collars), using standard protocols (for details see Krofel et al. 2013). GPS collars were equipped with remote GSM download technology and a programmable drop-off system ( 3 collars from TVP Positioning AB, Sweden and 2 collars from Vectronic Aerospace GmbH, Germany). GPS collars were scheduled to attempt 7-8 GPS fixes per day with higher frequency during the night. We usually visited these kill sites the day after lynx abandoned the kill (median: 4.5 days after the kill). At each kill site we recorded the coordinates with handheld GPS, prey species, sex, age category, date of kill and several habitat parameters. Whenever available, we collected mandible, femur and metatarsal bone.

According to the roe deer reproduction cycle, expected nutritional condition, and the hunting seasons the data was classified in three seasons: 1) late winter-spring (WS; January-April) when neonates are not available and there is no hunting, 2) summer (SU; May-August) when neonates become available and hunting is allowed for yearlings and adult males, and 3) autumn-early winter (AW; September-December) when fawns are older and hunting is allowed for all age and sex categories, except for adult and yearling males in the second half of the season.

\section{Estimation of age and nutritional condition of the predated and harvested animals}

Mandibles were cleaned and divided based on the eruption of teeth to fawns ( $<1$ year) and adults ( $\geq 1$ year). To age adult animals, we made histological thin-sections and counted dental and cementum layers (Klevezal 1996). We used $\mathrm{P}_{2}$ when possible, otherwise $\mathrm{P}_{3}$ or $\mathrm{M}_{1}$. Extracted teeth were decalcified with $5 \%$ nitric acid at room temperature for three to five days. After decalcification, teeth were sectioned using cryomicrotome (Leica CM 1850) to $15 \mu \mathrm{m}$ longitudinal sections. Weigert's hematoxylin was used as staining solution and layers in dentin and cementum of each section of tooth were counted using 100x translucent microscope.

We compared nutritional condition of the roe deer shot by hunters and killed by lynx by determining the proportion of roe deer with fat-depleted bone marrow, i.e. $<70 \%$ femur fat (Ransom 1965; Metz et al. 2012). In addition, to quantify the extent to which human harvest and lynx predation could be compensatory to other mortality, we calculated the proportion of animals with high risk of dying from starvation. Following previous studies (Franzmann and Arneson 1976; Sand et al. 2012) we used 20\% femur fat as a threshold to 
estimate and compare compensatory mortality between the two causes. Bone marrow was analysed using metatarsal and femoral bones according to Neiland (1970) and Ratcliffe (1980). A $4 \mathrm{~cm}$ long segment of bone marrow was cut out of the middle of the diaphysis of each bone, weighed, and dried at $60-65{ }^{\circ} \mathrm{C}$ to a constant weight (at least three days of drying). After drying, samples were put into an air-tight glass jar with silica gel in order to prevent condensation while cooling. Dried samples were weighed and proportion of the fat content in the bone marrow was calculated using regression equation given by Neiland (1970). Since only metatarsal bones were available for shot animals and only femurs for some of the lynx prey remains, for the latter we calculated corresponding values predicted for metatarsal bone using segmented regression (Muggeo 2003), because of the abrupt change in the response function. Data were derived from samples with both bones available from the same animal $(n=31)$ and following rules were used:

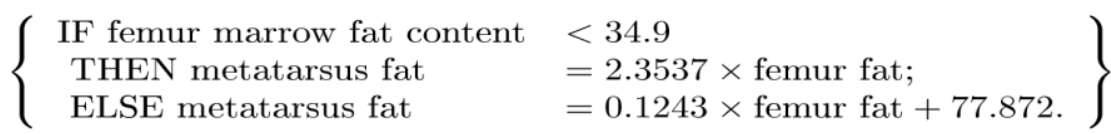

\section{Data analysis}

Sex and age structure

To test sex and age differences between human harvest and lynx predation we used generalized linear models (GLM; binomial error and a logit link function) with cause of death used as binary dependent variable (lynx predation, human harvest) and age $(0,1, \geq 2$ years), sex (male, female) and interaction age $\times$ sex as independent variables. We calculated all possible models with algorithm best subsets, selected the models with the lowest corrected Akaike Information Criterion (AICc) value, explored structure of all candidate models with $\triangle \mathrm{AICc}$ scores lower than 2 and calculated Akaike weights of the selected models (Burnham and Anderson 2002). The same approach as described above was used also for testing demographic differences among adult ( $\geqq 2$ years) roe deer with each year as individual category except for ages $>7$ years, which were pooled into one category to ensure that expected frequencies in each period by age class were $>5$ (Zar 1999). In addition, we repeated the same test with age as continuous variable. To test seasonal differences in lynx predation we used GLM with multinomial error and a logit link function, season as dependent variable (WS, SU, AW) and age, sex and their interaction as independent variables.

\section{Nutritional condition}

We also used GLM (binomial error, logit link function) to compare roe deer nutritional condition between the animals killed by lynx and humans. We tested effects of independent variables roe deer age $(0,1, \geq 2$ years), sex (male, female), season (WS, SU, $\mathrm{AW}$ ), cause of death (human harvest, lynx predation) and interactions season $\times$ age and season $\times$ sex on dependent binary variable the nutritional status (fat-depleted, non-fatdepleted bone marrow). For model selection we used the same approach as described above for demographic differences.

Lynx kill rate 
Lynx kill rate was calculated from the lynx telemetry data. The lynx kill rate was defined as the number of large prey (i.e. prey that lynx use for several days, so that the kill can be detected using GPS location cluster analysis) killed per unit time per lynx and was calculated from the average time between consecutive kills ( $n=114$ pairs) determined by the GPS location cluster analysis using thresholds of minimum two locations $<300 \mathrm{~m}$ and $>30 \mathrm{~h}$ apart (for details see Krofel et al. 2013). Since early displacements by dominant scavengers could bias data collected with this method (Ruth et al. 2010; Krofel et al. 2013), we used automatic video cameras to monitor consumption of simulated kills in the study area and showed that negligible part of carcasses are removed within the first $30 \mathrm{~h}$ period (Smole 2012; M. Krofel unpublished data). Because roe deer presented 88\% of killed large prey detected by the GPS location clusters (Krofel 2012), we used this proportion to determine kill rate on roe deer. We used average lynx home range size in the study area $\left(215 \mathrm{~km}^{2}\right.$; Krofel 2012$)$ to calculate average kill rate per lynx per area. Current lynx population in the study area is in decline and several lynx territories are vacant or occupied by only one of the lynx pair (Kos et al. 2012). Therefore we used density of 0.7-0.8 adult lynx / $100 \mathrm{~km}^{2}$ reported from Switzerland for the nearest saturated lynx population (Breitenmoser-Würsten et al. 2007) to estimate the potential lynx predation rate in Dinaric Mountains.

We used GLM to test seasonal differences in lynx kill rate with kill interval as dependent variable and season (WS, SU, AW), lynx status (male, single female, female with immobile kittens, family group) and interaction season $\times$ lynx status as independent variables. Due to asymmetric distribution of dependent variable we log transformed the kill rate data to achieve normal distribution. For model selection we used the same approach as described above for sex and age structure.

\section{Spatial distribution}

We estimated home range size (95\% minimal convex polygon) for each of the GPScollared lynx, overlaid it with map of roe deer densities $\left(1 \mathrm{~km}^{2}\right.$ resolution) and for each quadrant determined the number of roe deer shot by hunters and killed by lynx. We used absolute roe deer densities that were determined by a combination and linkages of pellet group counts data and removal data. Pellet groups were counted on $240400-\mathrm{m}^{2}$ plots randomly distributed throughout the study area and then used to calibrate removal data on various scales and for different mortality-causes (Adamič and Jerina 2010; Stergar et al. 2012). Since parts of some of the lynx home ranges were located outside Slovenia, where roe deer density data are not available, we removed these parts from further analysis. Quadrants were sorted according to the roe deer density from the lowest to the highest and pooled in ten equally large classes. For each class we calculated average roe deer density and number of roe deer killed by humans and lynx. We used Pearson chi-square $\left(\chi^{2}\right)$ test to compare distribution of human harvest and lynx predation. Due to the considerable difference in the number of animals killed by human harvest and by lynx predation, we relativized the data for each cause of mortality so that the sum of values for each equaled 100 and in this way visualized the data (Fig. 2). To better understand spatial predation patterns for individual lynx, we also calculated distances between consecutive kill sites for individual lynx determined by the GPS location cluster analysis and compared them using Kolmogorov-Smirnov test with distances between random points generated within the lynx home range. Since the presence of dependent kittens and distribution of roe deer densities might affect the distribution of kill sites, we calculated distances separately also only for kill sites of females during time periods without 
immobile kittens and males, and by including roe deer density in the selection of random points. Sequential random points were selected according to the roe deer density raster (Stergar et al. 2012) used as a reference probability surface generated with the Geospatial Modeling Environment (Beyer 2012). We used the same approach to get insight in the differences between spatial distribution of lynx predation and human harvest. We compared distances between consecutive lynx kill sites and equal number of randomly selected locations of animals shot by hunters within the same lynx home range.

\section{Results}

\section{Sex and age structure and seasonal differences}

We used data from 22,968 harvested roe deer and 78 roe deer killed by lynx. Sex ratio was similar in animals shot by hunters (55.9\% males) and killed by lynx (54.9\%, $P=0.54$ ), but there were differences in the age structure with higher proportion of fawns and yearlings in human harvest (Table 1). Compared to the human harvest, lynx were less likely to kill fawns than adults (odds ratio $=0.61$ ) and yearlings than adults (odds ratio=0.75), and among adults lynx were more likely to kill does (Table 2). We did not observe differences in the age structure of adult ( $\geq 2$ years) roe deer killed by hunters or lynx neither with age as categorical $(P=0.70)$ or continuous variable $(P=0.45)$ and no clear patterns in the data were observed (Fig. 1). We also did not observe seasonal differences in the sex or age structure of lynx prey (minimal $P>0.19$ ). But there were differences in the seasonal patterns between human harvest and lynx predation, as human harvest was limited to the hunting season (May-December), while lynx predation occurred throughout the year with the highest kill rate in summer and lowest in winterspring. Lynx kill rate mainly depended on lynx status $(P<0.001)$. The second best model also included variable season, however, the effect of the season was considerably less important (season: $P=0.17$, lynx status: $P=0.002$; Table 3 ).

\section{Nutritional condition}

Proportion of roe deer with fat-depleted bone marrow (i.e. animals with $<70 \%$ femur fat) was higher among lynx prey $(69 \%, n=48)$ than among harvested animals $(46 \%, n=197)$. The best model included variables age and cause of death (Table 4). Model predicted that roe deer killed by lynx are 1.9-times more likely to have fat-depleted bone marrow than animals shot by hunters. Animals in poor nutrition were also more likely among fawns than yearlings or adults (Table 4). None of the other models had $\triangle$ AICc score less than 2 . Proportion of compensatory mortality (i.e. animals with $<20 \%$ femur fat) was estimated to $5.1 \%$ among human harvest and $10.4 \%$ among lynx predation.

\section{Spatial distribution}

Total area monitored by the GPS-collared lynx amounted to $931 \mathrm{~km}^{2}$, where 74 roe deer killed by lynx were found and 1,607 animals were shot by hunters in 2006-2011. Average roe deer population density in the area was 2.73 roe deer $/ \mathrm{km}^{2}$ with relatively high variability (lowest decile $=1.02$ roe deer $/ \mathrm{km}^{2}$, highest decile $=5.73$ roe deer $/ \mathrm{km}^{2}$ ). Average kill interval for a monitored lynx was 1 roe deer killed per 7.64 days and 0.22 roe deer killed $/ \mathrm{km}^{2} /$ year, which represents approximately $8 \%$ of the local roe deer population. This is $59 \%$ lower than current human harvest inside the home ranges of the monitored lynx ( 0.54 roe deer shot $/ \mathrm{km}^{2} /$ year) and $79 \%$ lower than current human 
harvest in the region (i.e., Notranjska and Kočevska management units; 1.04 roe deer shot $/ \mathrm{km}^{2} /$ year). For a saturated lynx population the annual lynx predation would amount to $0.33-0.38$ roe deer killed $/ \mathrm{km}^{2}$, which represents approximately $12-14 \%$ of local roe deer population. This is 30-39\% lower than current human harvest inside the home ranges of the monitored lynx ( 0.54 roe deer shot $/ \mathrm{km}^{2} /$ year) and $63-68 \%$ lower than current human harvest in the region (i.e., Notranjska and Kočevska management units; 1.04 roe deer shot $/ \mathrm{km}^{2} /$ year).

We observed different patterns in the spatial distribution of killed roe deer in regard to the roe deer density $\left(\chi^{2}=34.8107, \mathrm{df}=9, P<0001\right)$. While the human harvest increased with higher roe deer density ( $r=0.93, n=10, P<0.001)$, the lynx predation was similar across the gradient of roe deer densities ( $r=0.18 ; n=10 ; P=0.62$; Fig. 2$)$.

Median distance between the lynx kill sites (median=5102 $\mathrm{m}, \mathrm{IQR}=3183, n=130$ ) was $26 \%$ shorter compared to the median distance between random locations (median=6859 $\mathrm{m}, \mathrm{IQR}=3603 \mathrm{~m}, n=130$, Kolmogorov-Smirnov test, $D=0.226, P=0.004)$. The same, although to a lesser extent was observed when we excluded lynx kill sites of females with immobile kittens (lynx kill sites: median=5307 m, IQR=2584 m, $n=115$; random locations: median=6724 m, IQR=5255 m, $n=115$, Kolmogorov-Smirnov test, $D=0.191$, $P=0.03$ ) and when roe deer densities were taken into account (lynx kill sites: median=5471 m, IQR=4910 m, $n=82$; random locations: median=6546 m, IQR=6281 m, $n=82$, Kolmogorov-Smirnov test, $D=0.202, P=0.05)$. On the other hand, distances between random locations were similar to distances between randomly selected locations of roe deer shot by hunters when roe deer densities were taken into account (random harvest locations: median $=5663 \mathrm{~m}, \mathrm{IQR}=5129 \mathrm{~m}, n=82$; random locations: median=5789 $\mathrm{m}, \mathrm{IQR}=5018 \mathrm{~m}, n=82$, Kolmogorov-Smirnov test, $D=0.146, P=0.35)$. The median distance between consecutive lynx kills was $34 \%$ shorter than the median distance between randomly selected locations of roe deer shot by hunters (lynx kill sites: median $=5467 \mathrm{~m}, \mathrm{IQR}=5166 \mathrm{~m}, n=82$; random harvest locations: median=8250 m, $\mathrm{IQR}=6246 \mathrm{~m}, n=82$, Kolmogorov-Smirnov test, $D=0.232, P=0.02)$.

\section{Discussion}

Human harvest of the roe deer in the northern Dinaric Mountains differs in several aspects from predation by the Eurasian lynx. These differences probably lead to different selection pressures on roe deer today compared to what the species was experiencing through its past evolution, especially when considering that anthropogenic mortality is today considerably higher than mortality sustained by lynx predation. This suggests caution needed in management planning in order to avoid unwanted side-effects of human harvest.

Patterns in differences between lynx predation and human harvest observed in Slovenia are different in comparison to the studies from other regions. For example, while we observed similar sex ratio in animals killed by hunters and lynx and higher proportion of young animals among roe deer shot by hunters, in a boreal region in Norway hunters shot more males and more adults than killed by lynx (Andersen et al. 2007). This differences are most likely result of strict regulations regarding sex and age structure for hunters in Slovenia, while no such regulations exist in Norway (Andersen et al. 2010) and it indicates one of the effects that hunting restrictions can have on the demographic structure of large mammal populations. Similar differences between Slovenia and Scandinavia were already observed in the sex and age structure of culled brown bears, which was considerably more biased towards males and young bears in Slovenia, where 
strict regulations regarding the size of shot bears are enforced (Bischof et al. 2008; Krofel et al. 2012).

In general, prey selection in respect to the nutritional condition is stronger among cursing compared to stalking predators (Husseman et al. 2003). Nevertheless, stalking predators can represent important natural selection pressure. For example, selection for animals in poorer condition was observed in previous studies on lynx predation on reindeer Rangifer tarandus (Haglund 1966; Pedersen et al. 1999) and red deer (Okarma 1984; Gossow and Honsig-Erlenburg 1985). We confirmed this role of stalking predators in maintaining healthy prey populations, as lynx-killed roe deer had considerably higher proportion of animals with depleted fat reserves and more starving animals (and consequently higher potential compensatory mortality) compared to animals shot by hunters. In contrast, no difference in nutritional condition was detected for roe deer killed by lynx or shot by hunters in Norway (Andersen et al. 2007). Possible explanation could be that higher roe deer densities in Slovenia enable lynx more selection in their hunting, because lower encounter rate with prey might force lynx in Scandinavia to invest greater effort at each hunting attempt. Selectivity in respect to the nutritional condition of prey can depend also on other parameters, such as habitat features (Okarma 1984), prey size and hunting success (Temple 1987).

At the European and country scale, it was shown that lynx predation has stronger effects on roe deer populations in less productive areas and in lower prey densities (Melis et al. $2009 ; 2010)$. We have now detected the same pattern also at the scale of individual lynx home range, as lynx kill rate was similar along the gradient of local roe deer densities, thus resulting in higher predation rate in areas with lower prey density. This indicates that lynx do not use their home range in respect to prey abundance. This is similar to observations in Poland (Schmidt 2008) and again, opposite to the results from Norway, where lynx increased use of patches with higher roe deer density, which were in winter concentrated due to artificial supplemental feeding (Moa et al. 2006), thus probably resulting in considerably higher variation in density, at least during winter, compared to Slovenia and Poland. In Poland, when faced with declining prey density, lynx adjusted spatial organization and increased their hunting effort (Schmidt 2008). It is unknown whether lynx use similar adaptations in Dinaric Mountains to adjust for spatial differences in prey availability.

Our results of lynx space use in relation to the prey abundance may seem in contradiction with predictions of the optimal foraging theory (Stephens et al. 2007). However, it must be kept in mind that Eurasian lynx is a stalker and ambush predator, whose hunting success depends also on surprise and vigilance of its prey (Breitenmoser and Breitenmoser-Würsten 2008). Therefore at certain point behavior of prey in a given patch may become more important for lynx foraging success than local prey density. In such 'predator-prey patch use games' (Brown and Kotler 2007) predators can anticipate and respond to the prey's fear responses. Thus the lynx' space use during foraging and distribution of its hunting attempts is expected to be a trade-off between local prey densities, changes in prey's vigilance and lynx' energy expenditure needed for the movement between the patches. In our case this was indicated by relatively long distances between consecutive lynx kills, which were, however, still closer to one another compared with distances between random locations within the home range or between locations of human harvest.

Lynx are hunting throughout the year with somewhat higher intensity at individual level in summer and autumn-early winter, when females are accompanied with kittens. In contrast, human harvest of roe deer is, like in many other countries, limited to the hunting 
season. Concentration of ungulate mortality to certain parts of the year, e.g. during the rutting season, when large part of males are shot, can have several negative side-effects, such as disruption of the breeding group, decreased fecundity, and threat to the population viability (Apollonio et al. 2011). In addition, predation evenly spread throughout the year promotes increased biodiversity, as it is beneficial for many scavenger species that depend on steady supply of carcasses (Wilmers et al. 2003).

Nowadays, there are probably no areas left in the northern temperate region where populations of large ungulates are not strongly influenced by man (Andersen et al. 2006). Comparison between Slovenia and Norway indicates how different human harvest of ungulates can be in relation to the natural mortality due to lynx predation in different parts of Europe. However, such diversity may not be something unwanted. Since researchers are becoming increasingly concerned about negative evolutionary and genetic side-effects of selection in human harvest (Harris et al. 2002; Festa-Bianchet 2003; Proaktor et al. 2007), diversity in hunting systems may mitigate some of these negative effects on a larger scale and especially in transboundary populations that are under the influence of different management regimes. Such an example was already observed in a transboundary brown bear population, where different hunting restrictions in the two neighbouring countries seem to buffer strong demographic effects of selective hunting in one of the countries (Krofel et al. 2012). Probably even more important role in buffering such unwanted side-effects of harvest of wild ungulates may be coming from the predators, such as Eurasian lynx. For example, since sex and age structure of lynx-killed roe deer corresponds to its availability (Jedrzejewski et al. 1993; Andersen et al. 2007), lynx predation could mitigate potential strong bias in hunting (e.g. towards males or larger individuals through trophy hunting). Since predators affect behavioural traits of their prey (Preisser et al. 2005), predation can be expected to buffer also against negative effects of hunting management on ungulate behaviour (e.g. semi-domestication of wild ungulates; Mysterud 2010). Such buffering effects are additional reason, why conservation or restoration of large predator guilds should be an integral part of wildlife management and important tool for prevention of biodiversity loss, as is becoming increasingly promoted by the results of recent studies (Beschta and Ripple 2009; Estes et al. 2011).

\section{LITERATURE}

Adamič M, Jerina K (2010) Ungulates and their management in Slovenia. In: Apollonio M,

Andersen R, Putman R (eds) European ungulates and their management in the 21st century.

Cambridge University Press, Cambridge, pp 507-526

Andersen R, Linnell JDC, Solberg EJ (2006) The future role of large carnivores on terrestrial trophic interactions: the northern temperate view. In: Danell K, Bergström R, Duncan P, Pastor J (eds) Large herbivore ecology, ecosystem dynamics and conservation. Cambridge University Press, Cambridge, pp 413-448

Andersen R, Karlsen J, Austmo LB, Odden J, Linnell JDC, Gaillard JM (2007) Selectivity of Eurasian lynx Lynx lynx and recreational hunters for age, sex and body condition in roe deer Capreolus capreolus. Wildlife Biol 13:467-474

Andersen R, Lund E, Solberg EJ, Saether BE (2010) Ungulates and their management in Norway. In: Apollonio M, Andersen R, Putman R (eds) European ungulates and their management in the 21st century. Cambridge University Press, Cambridge, pp 14-36 
Apollonio M, Andersen R, Putman R (2010) Present status and future challenges for European ungulate management. In: Apollonio M, Andersen R, Putman R (eds) European ungulates and their management in the 21st century. Cambridge University Press, Cambridge, pp 578-604

Apollonio M, Putman R, Grignolio S, Bartoš L (2011) Hunting seasons in relation to biological breeding seasons and the implications for the control or regulation of ungulate populations. In: Putman RJ, Apollonio M, Andersen R (eds) Ungulate Management in Europe: Problems and Practices. Cambridge University Press, Cambridge, pp 80-105

Beschta RL, Ripple WJ (2009) Large predators and trophic cascades in terrestrial ecosystems of the western United States. Biol Conserv 142:2401-2414. doi:10.1016/j.biocon.2009.06.015

Beyer HL (2012) Geospatial Modelling Environment (Version 0.6.0.0). http://www.spatialecology.com/gme. Accessed 14 February 2013.

Bischof R, Fujita R, Zedrosser A, Soderberg A, Swenson JE (2008) Hunting patterns, ban on baiting, and harvest demographics of brown bears in Sweden. J Wildlife Manage 72:79-88. doi:10.2193/2007-149

Breitenmoser-Würsten C, Zimmermann F, Stahl P, Vandel JM, Molinari-Jobin A, Molinari P, Capt S, Breitenmoser U (2007) Spatial and social stability of a Eurasian lynx Lynx lynx population: an assessment of 10 years of observation in the Jura Mountains. Wildlife Biol 13:365-380

Breitenmoser U, Breitenmoser-Würsten C (2008) Der Luchs: Ein Grossraubtier in der Kulturlandschaft. Salm Verlag, Wohlen and Bern

Brown JS, Kotler BP (2007) Foraging and the ecology of fear. In: Stephens DW, Brown JS, Ydenberg RC (eds) Foraging: behavior and ecology. The University of Chicago Press, Chicago, pp 437-480

Burnham KP, Anderson DR (2002) Model selection and multimodel inference: a practical information-theoretic approach. 2nd edn. Springer, New York

Ciuti S, Muhly TB, Paton DG, McDevitt AD, Musiani M, Boyce MS (2012) Human selection of elk behavioural traits in a landscape of fear. Proceedings of the Royal Society B: Biological Sciences 279:4407-4416. doi:10.1098/rspb.2012.1483

Coltman DW, O'Donoghue P, Jorgenson JT, Hogg JT, Strobeck C, Festa-Bianchet M (2003) Undesirable evolutionary consequences of trophy hunting. Nature 426:655-658

Estes JA, Terborgh J, Brashares JS, Power ME, Berger J, Bond WJ, Carpenter SR, Essington TE, Holt RD, Jackson JBC, Marquis RJ, Oksanen L, Oksanen T, Paine RT, Pikitch EK, Ripple WJ, Sandin SA, Scheffer M, Schoener TW, Shurin JB, Sinclair ARE, Soule ME, Virtanen R, Wardle DA (2011) Trophic downgrading of planet Earth. Science 333:301-306. doi:10.1126/science.1205106

Festa-Bianchet M (2003) Exploitative wildlife management as a selective pressure for the lifehistory evolution of large mammals. In: Festa-Bianchet M, Apollonio M (eds) Animal Behavior and Wildlife Conservation. Island Press, Washington, pp 191-207

Franzmann AW, Arneson PD (1976) Marrow fat in Alaskan moose femurs in relation to mortality factors. J Wildlife Manage 40:336-339 
Gervasi V, Nilsen EB, Sand H, Panzacchi M, Rauset GR, Pedersen HC, Kindberg J, Wabakken P, Zimmermann B, Odden J, Liberg O, Swenson JE, Linnell JDC (2011) Predicting the potential demographic impact of predators on their prey: a comparative analysis of two carnivoreungulate systems in Scandinavia. J Anim Ecol 81:443-454. doi:10.1111/j.13652656.2011.01928.x

Ginsberg JR, Milner-Gulland EJ (1994) Sex-biased harvesting and population dynamics in ungulates: implications for conservation and sustainable use. Conserv Biol 8:157-166

Gossow H, Honsig-Erlenburg P (1985) Several predation aspects of red deer-specialized lynx. 17th Intern. Congr. IUGB, Brussels, Bruselj,

Haglund B (1966) Winter habits of the lynx (Lynx lynx L.) and wolverine (Gulo gulo L.) as revealed by tracking in the snow. Viltrevy 4:81-229

Harris RB, Wall WA, Allendorf FW (2002) Genetic consequences of hunting: what do we know and what should we do? Wildlife Soc B 30:634-643

Heurich M, Möst L, Schauberger G, Reulen H, Sustr P, Hothorn T (2012) Survival and causes of death of European roe deer before and after Eurasian lynx reintroduction in the Bavarian Forest National Park. Eur J Wildlife Res 58:567-578. doi:10.1007/s10344-011-0606-y

Hewison AJM, Vincent JP, Angibault JM, Delorme D, Van Laere G, Gaillard JM (1999) Tests of estimation of age from tooth wear on roe deer of known age: variation within and among populations. Can J Zoolog 77:58-67

Husseman JS, Murray DL, Power G, Mack C, Wenger CR, Quigley H (2003) Assessing differential prey selection patterns between two sympatric large carnivores. Oikos 101:591601

Jedrzejewska B, Jedrzejewski W (1998) Predation in vertebrate communities: The Białowieża Primeval Forest as a case study. Springer, Heidelberg

Jedrzejewski W, Apollonio M, Jedrzejewska B, Kojola I (2011) Ungulate-large carnivore relationships in Europe. In: Putman RJ, Apollonio M, Andersen R (eds) Ungulate management in Europe: problems and practices. Cambridge University Press, Cambridge, pp 284-318

Jedrzejewski W, Schmidt K, Milkowski L, Jedrzejewska B, Okarma H (1993) Foraging by lynx and its role in ungulate mortality - the local (Bialowieza Forest) and the Palearctic viewpoints. Acta Theriol 38:385-403

Jelenko I, Jerina K, Pokorny B (2010) Impact of environmental factors on the appearance and distribution of dental fluorosis in roe deer (Capreolus capreolus L.) in eastern Slovenia. Zbornik gozdarstva in lesarstva 92: 21-32

Klevezal GA (1996) Recording strucutres of mammals, determination of age and reconstruction of life histrory. A. A. Balkema, Brookfield

Kos I, Koren I, Potočnik H, Krofel M (2012) Status and distribution of Eurasian lynx (Lynx lynx) in Slovenia from 2005 to 2009. Acta Biologica Slovenica 55:49-63

Kos I, Potočnik H, Skrbinšek T, Skrbinšek Majić A, Jonozovič M, Krofel M (2005) Lynx in Slovenia. 2nd edn. University of Ljubljana, Ljubljana

Krofel M (2012) Predation-related interspecific interactions in Eurasian lynx (Lynx lynx) in northern Dinaric Mountains. Doctorate thesis, University of Ljubljana, Ljubljana 
Krofel M, Huber D, Kos I (2011) Diet of Eurasian lynx Lynx lynx in the northern Dinaric Mountains (Slovenia and Croatia): Importance of edible dormouse Glis glis as alternative prey. Acta Theriol 56:315-322. doi:10.1007/s13364-011-0032-2

Krofel M, Jonozovič M, Jerina K (2012) Demography and mortality patterns of removed brown bears in a heavily exploited population. Ursus 23:91-103. doi:10.2192/URSUS-D-10-00013.1

Krofel M, Skrbinšek T, Kos I (2013) Use of GPS location clusters analysis to study predation, feeding, and maternal behavior of the Eurasian lynx. Ecol Res 28:103-116. doi:10.1007/s11284-012-1005-x

Langvatn R, Loison A (1999) Consequences of harvesting on age structure, sex ratio and population dynamics of red deer Cervus elaphus in central Norway. Wildlife Biol 5:213-223

Linnell JDC, Zachos FE (2011) Status and distribution patterns of European ungulates: genetics, population history and conservation. In: Putman R, Apollonio M, Andersen R (eds) Ungulate management in Europe: problems and practices. Cambridge University Press, Cambridge, pp $12-53$

Melis C, Basille M, Herfindal I, Linnell JDC, Odden J, Gaillard JM, Hogda KA, Andersen R (2010) Roe deer population growth and lynx predation along a gradient of environmental productivity and climate in Norway. Ecoscience 17:166-174. doi:10.2980/17-2-3314

Melis C, Jedrzejewska B, Apollonio M, Barton KA, Jedrzejewski W, Linnell JDC, Kojola I, Kusak J, Adamic M, Ciuti S, Delehan I, Dykyy I, Krapinec K, Mattioli L, Sagaydak A, Samchuk N, Schmidt K, Shkvyrya M, Sidorovich VE, Zawadzka B, Zhyla S (2009) Predation has a greater impact in less productive environments: variation in roe deer, Capreolus capreolus, population density across Europe. Global Ecol Biogeogr 18:724-734. doi:10.1111/j.1466-8238.2009.00480.x

Metz MC, Smith DW, Vucetich JA, Stahler DR, Peterson RO (2012) Seasonal patterns of predation for gray wolves in the multi-prey system of Yellowstone National Park. J Anim Ecol 81:553-563. doi:10.1111/j.1365-2656.2011.01945.x

Milner JM, Nilsen EB, Andreassen HP (2007) Demographic side effects of selective hunting in ungulates and carnivores. Conserv Biol 21:36-47. doi:10.1111/j.1523-1739.2006.00591.x

Moa PF, Herfindal I, Linnell JDC, Overskaug K, Kvam T, Andersen R (2006) Does the spatiotemporal distribution of livestock influence forage patch selection in Eurasian lynx Lynx lynx? Wildlife Biol 12:63-70

Muggeo VMR (2003) Estimating regression models with unknown break-points. Statistics in Medicine 22:3055-3071. doi:10.1002/sim.1545

Mysterud A (2010) Still walking on the wild side? Management actions as steps towards 'semidomestication' of hunted ungulates. J Appl Ecol 47:920-925. doi:10.1111/j.13652664.2010.01836.x

Neiland KA (1970) Weight of dried marrow as indicator of fat in caribou femurs. J Wildlife Manage 34:904-907

Nilsen EB, Linnell JDC, Odden J, Andersen R (2009) Climate, season, and social status modulate the functional response of an efficient stalking predator: the Eurasian lynx. J Anim Ecol 78 (4):741-751. doi:10.1111/j.1365-2656.2009.01547.x 
Okarma H (1984) The physical condition of red deer falling a prey to the wolf and lynx and harvested in the Carpathian Mountains. Acta Theriol 29:283-290

Okarma H (1995) The trophic ecology of wolves and their predatory role in ungulate communities of forest ecosystems in Europe. Acta Theriol 40:335-386

Pedersen VA, Linnell JDC, Andersen R, Andren H, Linden M, Segerstrom P (1999) Winter lynx Lynx lynx predation on semi-domestic reindeer Rangifer tarandus in northern Sweden. Wildlife Biol 5:203-211

Perko D, Orožen Adamič M (1998) Slovenija: pokrajine in ljudje. Mladinska knjiga, Ljubljana

Poličnik H, Pokorny B, Varljen Bužan E, Kryštufek B (2011) Spreminjanje spola uplenjenih/izločenih parkljarjev - le čemu? Kontrola z analizo genskega lokusa SRY. Lovec 94:75-76

Preisser EL, Bolnick DI, Benard MF (2005) Scared to death? The effects of intimidation and consumption in predator-prey interactions. Ecology 86 (2):501-509. doi:10.1890/04-0719

Proaktor G, Coulson T, Milner-Gulland EJ (2007) Evolutionary responses to harvesting in ungulates. J Anim Ecol 76:669-678. doi: 10.1111/j.1365-2656.2007.01244.x

Putman R (2011) A review of the various legal and administrative systems governing management of large herbivores in Europe. In: Putman R, Apollonio M, Andersen R (eds) Ungulate management in Europe: problems and practices. Cambridge University Press, Cambridge, pp 54-79

Ransom AB (1965) Kidney and marrow fat as indicators of white-tailed deer condition. J Wildlife Manage 29:397-398

Ratcliffe PR (1980) Bone marrow fat as an indicator of condition in roe deer. Acta Theriol 25:333340

Ruth TK, Buotte PC, Quigley HB (2010) Comparing ground telemetry and global positioning system methods to determine cougar kill rates. J Wildlife Manage 74 (5):1122-1133. doi:10.2193/2009-058

Sand H, Wikenros C, Ahlqvist P, Strømseth TH, Wabakken P (2012) Comparing body condition of moose (Alces alces) selected by wolves (Canis lupus) and human hunters: consequences for the extent of compensatory mortality. Can J Zool 90:403-412. doi:10.1139/z2012-007

Schmidt K (2008) Behavioural and spatial adaptation of the Eurasian lynx to a decline in prey availability. Acta Theriol 53:1-16

Slovenia Forest Service (2007) Dolgoročni načrt za IV Notranjsko lovsko upravljavsko območje za obdobje 2007 - 2016. . Slovenia Forest Service, Postojna

Smole I (2012) The importance of large herbivore carcasses for vertebrate scavengers in Dinaric forests of Slovenia. Diploma thesis. University of Ljubljana, Ljubljana

Stephens DW, Brown JS, Ydenberg RC (2007) Foraging: behavior and ecology. The University of Chicago Press, Chicago

Stergar M, Borkovič D, Hiršelj J, Kavčič I, Krofel M, Mrakič M, Troha R, Videmšek U, Vrčon B, Jerina K (2012) Estimation of wild ungulate densities with a combined method of pellet group counting and removal data. Biotechnical faculty, University of Ljubljana, Ljubljana 
Temple SA (1987) Do predators always capture substandard individuals disproportionately from prey populations? Ecology 68:669-674

Wilmers CC, Crabtree RL, Smith DW, Murphy KM, Getz WM (2003) Trophic facilitation by introduced top predators: grey wolf subsidies to scavengers in Yellowstone National Park. J Anim Ecol 72 (6):909-916

Wright GJ, Peterson RO, Smith DW, Lemke TO (2006) Selection of northern Yellowstone elk by gray wolves and hunters. J Wildlife Manage 70 (4):1070-1078

Zar JH (1999) Biostatistical analysis. Prentice Hall, Upper Saddle River, New Jersey, USA 
Figure 1 Comparison of age structure of adult ( $\geq 2$ years) European roe deer killed by hunters (black, $n=86$ ) and Eurasian lynx (white, $n=26$ ) in Slovenia.

Figure 2 Comparison of spatial distribution of human harvest (black, $n=1607$ ) and lynx kill sites (white, $n=57$ ) in a gradient of European roe deer densities in Slovenia. Grid resolution was $1 \mathrm{~km}^{2}$ and quadrats were separated in ten equal classes according to the roe deer density. Average roe deer density for each class is given and proportion of removals per roe deer density class for each cause of mortality. 
Table 1 Relative sex and age structure of European roe deer shot by hunters $(n=22,968)$ and killed by Eurasian lynx $(n=63)$.

\begin{tabular}{|c|c|c|c|c|c|c|}
\hline & \multicolumn{2}{|c|}{ Fawns } & \multicolumn{2}{|c|}{ Yearlings } & \multicolumn{2}{|c|}{ Adults } \\
\hline & Males & Females & Males & Females & Males & Females \\
\hline Human harvest & 0.181 & 0.198 & 0.127 & 0.103 & 0.251 & 0.139 \\
\hline Lynx predation & 0.127 & 0.063 & 0.079 & 0.063 & 0.349 & 0.317 \\
\hline
\end{tabular}


Table 2 Parameter estimates and test statistics for the best general linear models $(\triangle \mathrm{AICc}<2)$ explaining sex and age structure of European roe deer shot by hunters in comparison to animals killed by lynx (human harvest coded as 0 , lynx predation as 1). One level of each categorical variable served as contrast (estimate $=0$ ) for the remaining levels of that variable. $F=$ female, $M=$ male, $\omega_{\mathrm{i}}=$ model Akaike's weights. Complete list of models with their AICc values is given in Online Resource 1.

\begin{tabular}{|c|c|c|c|c|c|c|}
\hline Model & Variable (level) & Estimate & Odds ratio & Wald statistic & $P$ & $\omega_{\mathrm{i}}$ \\
\hline \multirow[t]{6}{*}{1} & Age & & & 28.5 & & 0.57 \\
\hline & (fawns vs. adults) & -0.490 & 0.613 & & 0.01 & \\
\hline & (yearlings vs. adults) & -0.286 & 0.751 & & 0.17 & \\
\hline & Age $\times$ sex & & & 7.1 & & \\
\hline & $\mathrm{F}$ fawns vs. $\mathrm{M}$ adults & -0.298 & 0.742 & & 0.12 & \\
\hline & F yearlings vs. $M$ adults & -0.005 & 0.995 & & 0.98 & \\
\hline \multirow[t]{8}{*}{2} & Age & & & 28.1 & & 0.43 \\
\hline & (fawns vs. adults) & -0.501 & 0.606 & & 0.01 & \\
\hline & (yearlings vs. adults) & -0.291 & 0.748 & & 0.17 & \\
\hline & Age $\times \operatorname{sex}$ & & & 6.4 & & \\
\hline & F fawns vs. $M$ adults & -0.311 & 0.733 & & 0.11 & \\
\hline & $\mathrm{F}$ yearlings vs. $\mathrm{M}$ adults & -0.048 & 0.954 & & 0.82 & \\
\hline & Sex & & & 0.4 & & \\
\hline & F vs. M & -0.081 & 0.922 & & 0.54 & \\
\hline
\end{tabular}


Table 3 Parameter estimates and test statistics for the best general linear models $(\triangle \mathrm{AICc}<2)$ explaining effects of season and predator status (female with immobile kittens, family group, male, and single female) on the kill rate (time interval between consecutive kills) of Eurasian lynx on European roe deer in northern Dinaric Mountains. One level of each categorical variable served as contrast (estimate $=0$ ) for the remaining levels of that variable. $\mathrm{F}+\mathrm{IK}=$ female with immobile kittens, $\mathrm{FG}=$ family groups, $\mathrm{M}=$ single male, $\mathrm{F}=$ single female, $\mathrm{WS}=$ winter-spring, $\mathrm{SU}=$ summer, AW = autumn-winter, $\omega_{\mathrm{i}}=$ model Akaike's weights.

\begin{tabular}{|c|c|c|c|c|c|c|}
\hline Model & Variable (level) & $\beta$ & $S E(\beta)$ & $t$ & $P$ & $\omega_{i}$ \\
\hline 1 & Lynx status & & & & $<0.001$ & 0.52 \\
\hline \multirow{10}{*}{2} & (FG vs. F+IK) & -0.255 & 0.089 & -2.88 & 0.005 & \\
\hline & (M vs. F+IK) & 0.298 & 0.089 & 3.36 & 0.001 & \\
\hline & (F vs. F+IK) & 0.047 & 0.088 & 0.53 & 0.60 & \\
\hline & \multicolumn{4}{|l|}{ Lynx status } & 0.002 & 0.47 \\
\hline & $(\mathrm{FG}$ vs. F+IK) & -0.195 & 0.094 & -2.07 & 0.041 & \\
\hline & (M vs. F+IK) & 0.275 & 0.094 & 2.93 & 0.004 & \\
\hline & (F vs. F+IK) & 0.123 & 0.099 & 1.23 & 0.22 & \\
\hline & Season & & & & 0.17 & \\
\hline & (SU vs. WS) & 0.237 & 0.155 & 1.53 & 0.13 & \\
\hline & (AW vs. WS) & -0.059 & 0.157 & -0.37 & 0.71 & \\
\hline
\end{tabular}


Table 4 Parameter estimates and test statistics for the single best general linear model explaining proportion of European roe deer with fat-depleted bone marrow (all other models had $\Delta \mathrm{AIC}>2$ ). One level of each categorical variable served as contrast (estimate $=0$ ) for the remaining levels of that variable. $\omega_{\mathrm{i}}=$ model Akaike's weight.

\begin{tabular}{|c|c|c|c|c|c|c|}
\hline Model & Variable (level) & estimate & Odds ratio & Wald statistic & $P$ & $\omega_{\mathrm{i}}$ \\
\hline \multirow[t]{5}{*}{1} & Age & & & 29.4 & & 1 \\
\hline & (fawns vs. adults) & 0.925 & 2.52 & & $<0.0001$ & \\
\hline & (yearlings vs. adults) & -0.146 & 0.86 & & 0.56 & \\
\hline & Cause of death & & & 12.51 & & \\
\hline & (lynx vs. harvest) & 0.656 & 1.93 & & $<0.001$ & \\
\hline
\end{tabular}

